\title{
Review Article \\ Exergaming as a Strategic Tool in the Fight against Childhood Obesity: A Systematic Review
}

\author{
Carminda Maria Goersch Fontenele Lamboglia, ${ }^{1}$ Vanina Tereza Barbosa Lopes da Silva, \\ José Eurico de Vasconcelos Filho, ${ }^{2}$ Mônica Helena Neves Pereira Pinheiro, ${ }^{3}$ \\ Marilene Calderaro da Silva Munguba, ${ }^{4}$ Francisco Valmar Isaias Silva Júnior, ${ }^{2}$ \\ Fernando Alberto Ramirez de Paula, ${ }^{3}$ and Carlos Antônio Bruno da Silva ${ }^{1,5}$ \\ ${ }^{1}$ Collective Health Program, University of Fortaleza (UNIFOR), Avenida Washington Soares, 1321 Edson Queiróz, \\ 60.811-905 Fortaleza, CE, Brazil \\ ${ }^{2}$ Center for Application of Information Technology, Innovation Laboratory, University of Fortaleza (UNIFOR), \\ Avenida Washington Soares, 1321 Edson Queiróz, 60.811-905 Fortaleza, CE, Brazil \\ ${ }^{3}$ Center for Health Sciences-Physical Education, University of Fortaleza (UNIFOR), Avenida Washington Soares, \\ 1321 Edson Queiróz, 60.811-905 Fortaleza, CE, Brazil \\ ${ }^{4}$ Center for Health Sciences-Occupational Therapy, University of Fortaleza (UNIFOR), Avenida Washington Soares, \\ 1321 Edson Queiróz, 60.811-905 Fortaleza, CE, Brazil \\ ${ }^{5}$ University of Fortaleza (UNIFOR), Avenida Washington Soares, 1321 Edson, Queiróz, 60.811-905 Fortaleza, CE, Brazil
}

Correspondence should be addressed to Carlos Antônio Bruno da Silva; carlosbruno@unifor.br

Received 11 January 2013; Revised 20 July 2013; Accepted 5 September 2013

Academic Editor: Reza Majdzadeh

Copyright (C) 2013 Carminda Maria Goersch Fontenele Lamboglia et al. This is an open access article distributed under the Creative Commons Attribution License, which permits unrestricted use, distribution, and reproduction in any medium, provided the original work is properly cited.

\begin{abstract}
Improper use of electronic media is considered a major contributing factor to childhood obesity. However, exergames, a new generation of active games, have made it possible to combine electronic entertainment with physical exercise. The purpose of this systematic review was to analyze the use of exergaming as a strategic tool in the fight against childhood obesity. Information was retrieved from the databases SciELO, LILACS, Pubmed, Ebsco, and Science Direct, using the search words "egames," "exergames," "exergaming," "new generation of video games," "active video games," "energy expenditure," "body composition," and "physical activity" in English and Portuguese, covering the period January 2008 to April 2012. Nine articles met the inclusion criteria. Exergaming was found to increase physical activity levels, energy expenditure, maximal oxygen uptake, heart rate, and percentage of physical activity engaged in and to reduce waist circumference and sedentary screen time. Thus, exergaming may be considered a highly relevant strategic tool for the adoption of an active and healthy lifestyle and may be useful in the fight against childhood obesity.
\end{abstract}

\section{Introduction}

Within the context of the technological advances of the 21st century, improper use of electronic media has become a major contributing factor to the growing problem of childhood obesity [1].

Recent studies have shown a positive relation between time spent in front of TV and increasing adiposity among school children. Thus, according to Baughcum et al. [2], sedentary behaviors associated with electronic entertainment (computers, TV, and video games) contribute to increasing the prevalence of overweight and obesity in children.

The number of hours spent in front of TV may be directly related to the increase in body mass index (BMI), cholesterol levels, smoking prevalence, and loss of fitness [3]. Similar results were reported by Carvalhal et al. [4] who found time spent with video gaming to be directly proportional to the increase in BMI in 7-9-year-old children.

In a cross-sectional population-based study involving 4,964 school children aging 4-10 years, Corso et al. [5] 
observed a significant association between the presence of overweight/obesity and daily time spent in front of the computer.

Nevertheless, in view of this problematic, a more healthfriendly entertainment technology has been developed with the purpose of associating video gaming with physical fitness [6].

Some authors have proposed the use of interactive digital tools in the form of serious games focused on rehabilitation and promotion of healthy habits. These tools have been shown to result in significant learning and transference of contents to real-life scenarios $[7,8]$.

Serious games are interactive digital tools based on design principles which go beyond mere entertainment and make use of the recreational motivation behind games to convey a message, teach contents and practices, rehabilitate users, or provide useful experiences. Entertainment and fun are not their primary purpose; instead, serious games are given a meaning and a practical objective in order to solve specific real-life problems [9].

The use of serious games for purposes of rehabilitation, health promotion, physical fitness, and health monitoring may be relevant for overweight or obese children in need of nutritional reeducation or physical rehabilitation, by way of game-related motor skill training and health indicator evaluation and analysis [7].

Health professionals are consequently beginning to use serious games as a strategy to promote health education and well-being, for example, by distracting patients during painful medical procedures, managing therapeutic interventions, and designing simulations of rehabilitation and motor skill training. Other serious games are intended to build healthy habits and behaviors related to food and physical exercise [9].

In the realm of physical exercise and fitness, a new technological concept has emerged referred to as exertainment or exergaming. According to Sinclair et al. [10], quoted by Vaghetti and Botelho [11], these expressions are portmanteaus combining the words "game," "exercise," and "entertainment" in an attempt to make physical exercise more attractive by association with video game imagery [9].

Thus, the combination of interactive video games and physical exercise constitutes an innovative tool in the fight against childhood obesity as it stimulates and reinforces the habit of physical activity in an environment that is both entertaining and purposeful. The benefits include increased levels of physical activity, reduced consumption of lownutrition foods, and increased energy expenditure, with direct repercussions on the main variables associated with childhood obesity [12].

Given this context, this highlights the need to deepen the knowledge of an innovative and unexplored way to combat childhood obesity. Thus, the purpose of the present systematic review was to evaluate the use of exergaming as a strategic tool for the promotion of healthy behaviors in the fight against childhood obesity.

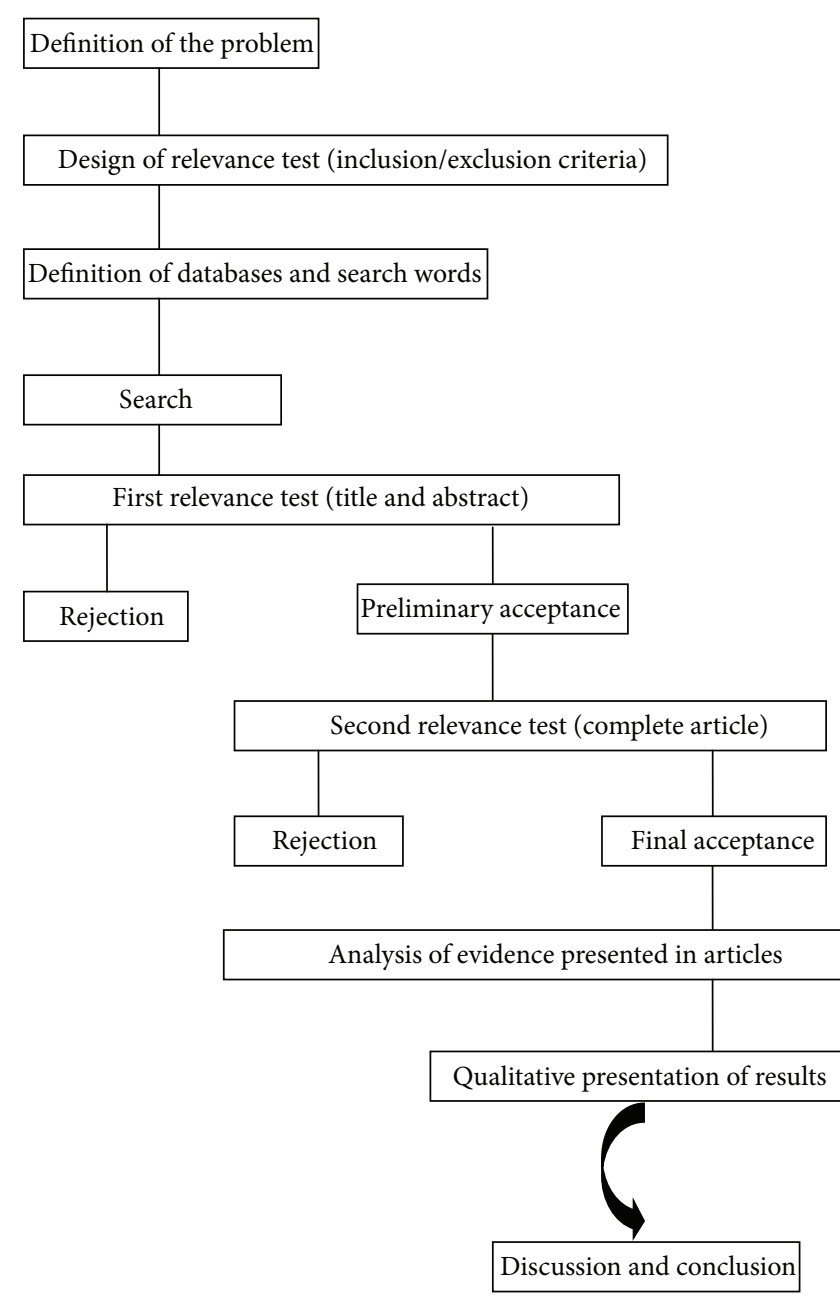

FIgURE 1: Flowchart of the systematic review.

\section{Materials and Methods}

This is a systematic review of the scientific literature on exergaming as a strategic tool for the promotion of physical activity, followed by critical analysis and synthesis [13].

Information was retrieved from the databases SciELO (Scientific Electronic Library Online), LILACS (Literature in the Health Sciences in Latin America and the Caribbean), Pubmed, Ebsco, and Science Direct, using the search words and phrases "egames," "exergames," "exergaming," "new generation of video games," "active video games," "energy expenditure," "body composition," and "physical activity." These terms are key words rather than health descriptors due to the novelty of the innovative concepts employed in the field.

The study was carried out following the steps illustrated in Figure 1. Initially, the problem was defined, followed by the establishment of inclusion/exclusion criteria and the selection of databases and search words. Then, the databases were searched for relevant articles. The title and abstract were used initially to determine the relevance, followed by the reading of the complete text of the selected articles. Finally, the articles were analyzed with regard to methodology and results, and the findings were summarized in Table 1. 


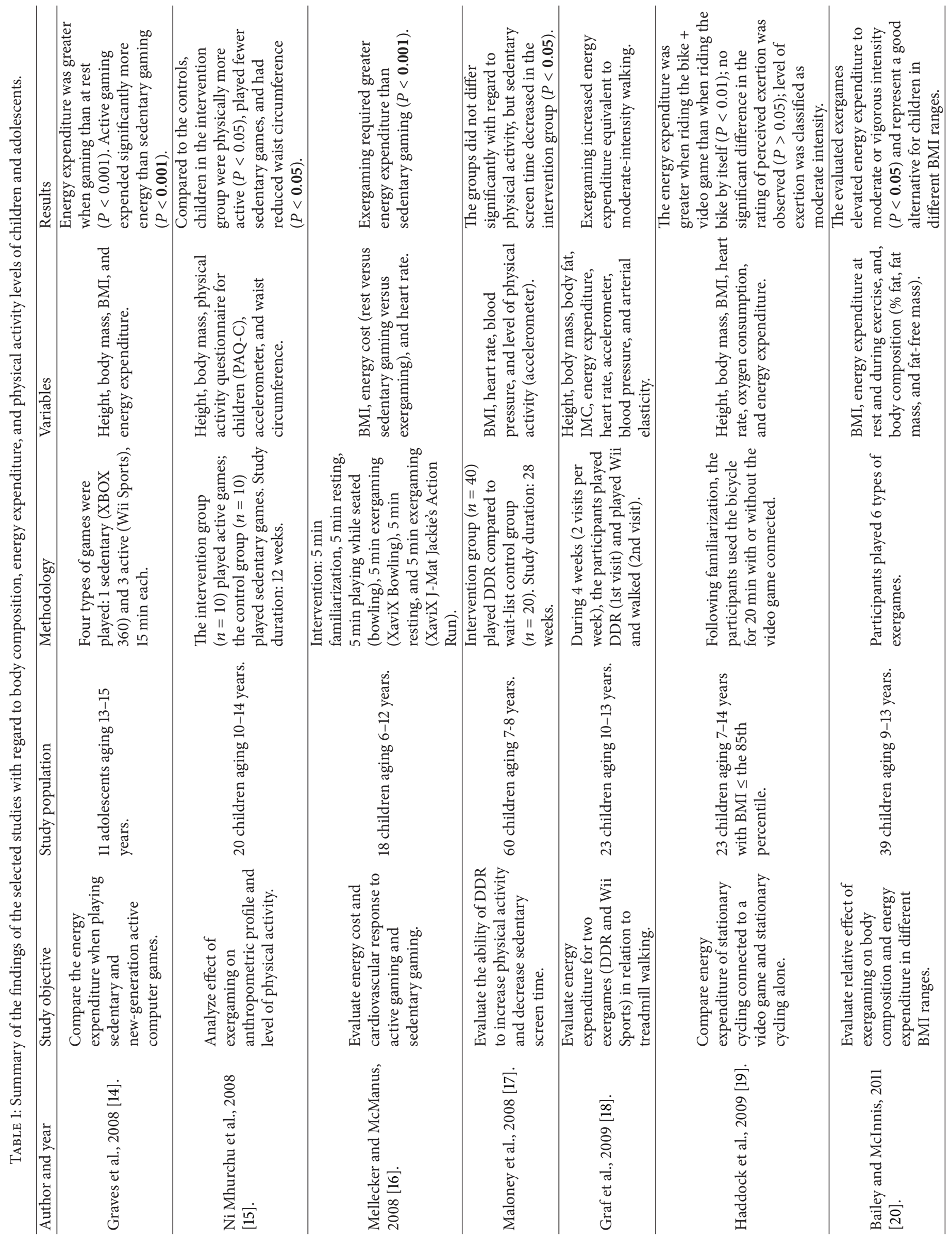




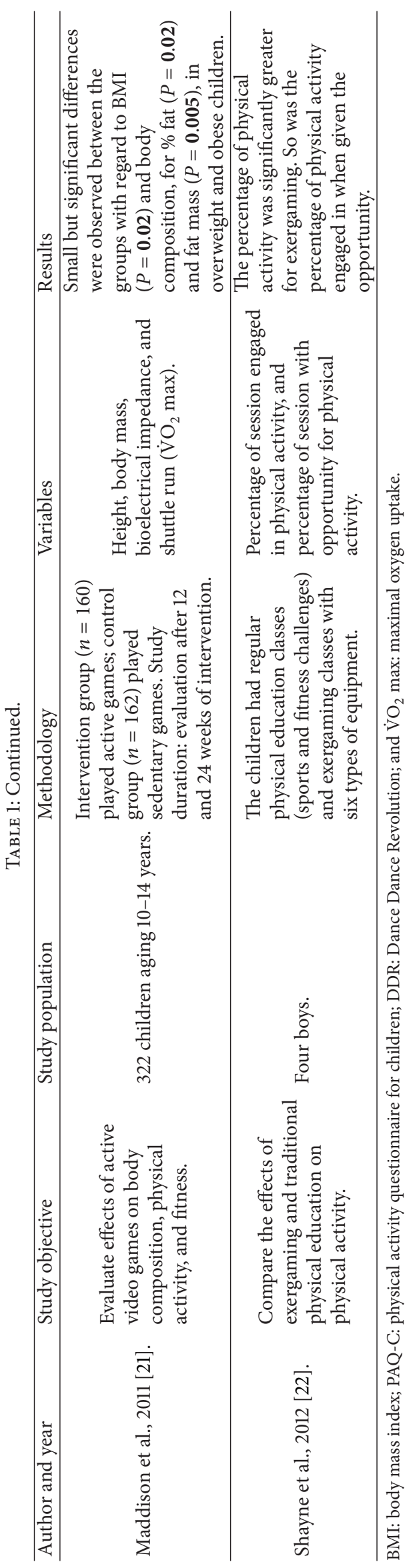


The search was limited to scientific papers in Portuguese and English, published between January 2008 and April 2012, in relevant and high-impact journals. No grey literature was used.

To be eligible, the studies should adopt the following:

(i) focus on children and adolescents aging 6-15 years;

(ii) be cross-sectional and experimental;

(iii) evaluate energy expenditure during exergaming;

(iv) discuss the association between active games and chealth behavior;

(v) evaluate changes in the level of physical activity, body composition, musculoskeletal system, and cardiovascular system.

Studies that were not eligible were those which

(i) were not available in full-text format;

(ii) focused on the use of exergaming for rehabilitation or cognitive therapy;

(iii) did not quantify the following variables: health behavior, energy expenditure, body composition, musculoskeletal system, and cardiovascular system.

Using the above search criteria, 223 potentially relevant publications were initially identified. The first screening of relevance reduced this number to 37 articles $(\mathrm{SciELO}=0$, LILACS $=0$, Pubmed $=23$, Ebsco $=10$, and Science Direct $=4$ ), and, following a complete text analysis, a final sample of 9 articles was defined. The remaining articles were excluded for a number of reasons: being on the adverse effects of the misuse of video games, focusing on adult subjects, using interactive video games for therapeutic purposes, analyzing variables not included in the present study, and unavailability of the full text.

The quality of the selected studies was determined based on the impact factor of the respective journals, all of which ranking above B3 in the Qualis System (CAPES), indicating the potential importance of the studies to the present review.

A final full-text analysis of each of the 9 selected articles was carried out by four independent reviewers using a standardized instrument. Finally, the information extracted from each article was discussed among the four reviewers until a consensus was reached.

The aspects considered included the folowing: (i) the year of publication, (ii) the relevance of the study objective to the present review, (iii) the participants (including sample, age range, and functional and physical conditions), (iv) methodology, (v) variables employed, and (vi) main findings. The significance level and effect size were mentioned in the main findings.

The selected studies were cross-sectional, longitudinal, and interventional (covering at least four weeks of intervention), and they involved children of both genders.

The findings were summarized in Table 1 with the following headings: author and year, study objective, target population, methodology, variables, and results.

\section{Results}

Nine articles met the inclusion criteria and were included in the analysis. All were published in English in the period 2008-2012.

From the papers selected, we chose not to use statistical analysis to evaluate the information, at this moment, because the proposal was to identify, select, and critically analyze studies relevant substantial thematic established. Therefore, Table 1 shows these publications in chronological order.

The study "Energy expenditure in adolescents playing new generation computer games" [14] compares the energy expenditure of adolescents when playing sedentary (XBOX 360) and new-generation active computer games (Wii Bowling, Wii Tennis and Wii Boxing). The authors found energy expenditure (expressed in $\mathrm{kl} / \mathrm{kg} / \mathrm{min}$ ) to be significantly greater when playing active games (bowling: 190.6; tennis: 202.5; boxing: 198.1) than when playing sedentary games (125.5) or when at rest $(81.3)(P<0.001)$. However, the exercise associated with the active games was not of highenough intensity to contribute towards the recommended daily amount of exercise in children. Nevertheless, given the current prevalence of childhood overweight and obesity, positive behaviors such as exergaming should be encouraged.

In the experimental study "Couch potatoes to jumping beans: a pilot study of the effect of active video games on physical activity in children" [15], the effect of exergaming on children's anthropometric profile and level of physical activity was evaluated. The participants were randomized to play either active video games ("EyeToy active games" and "dance mat") or conventional sedentary games (control group). After 12 weeks, the children in the intervention groups displayed higher levels of physical activity (+194 counts/min) (95\%, CI 32 , and 310 counts; $P=0.04$ ) measured with an accelerometer, while the mean difference in waist circumference between the groups was $-1.4 \mathrm{~cm}(95 \%, \mathrm{CI}-2.68$, and $-0.04 \mathrm{~cm} ; P=$ 0.04).

The experimental study "Energy expenditure and cardiovascular responses to seated and active gaming in children" [16] examined children's energy cost and cardiovascular response to active gaming, using the following protocol: $5 \mathrm{~min}$ for familiarization, $5 \mathrm{~min}$ resting, $5 \mathrm{~min}$ playing while seated (bowling), 5 min exergaming (XaviX Bowling), $5 \mathrm{~min}$ resting, and $5 \mathrm{~min}$ exergaming (XaviX J-Mat Jackie's Action Run). The energy expenditure was significantly higher during gaming in general than during rest $\left(0.96 \mathrm{kcal} \cdot \mathrm{min}^{-1}\right)$ $(P<0.001)$ and significantly higher $(P<0.001)$ during active gaming (XaviX Bowling: $1.89 \mathrm{kcal} \cdot \mathrm{min}^{-1}$; XaviX J-Mat Jackie's Action Run: $5.23 \mathrm{kcal} \cdot \mathrm{min}^{-1}$ ) than during seated gaming $\left(1.31 \mathrm{kcal} \cdot \mathrm{min}^{-1}\right)$. With regard to cardiovascular response, the cardiac rate increased significantly $(P<0.001)$ in all games when compared to mean resting values ( 81 beats/min). Rates were also significantly higher $(P<0.001)$ for exergaming (XaviX Bowling: 102 beats/min; XaviX J-Mat Jackie's Action Run: 160 beats/min) than for seated gaming ( 89 beats/min) [16].

Maloney et al. [17] evaluated the effect of another type of exergame ("Dance Dance Revolution") in a study entitled 
"A pilot of a video game (DDR) to promote physical activity and decrease sedentary screen time." The children in the intervention group were requested to play the exergame (DDR) at home for 28 weeks. The intervention group and the control group did not differ significantly with regard to sedentary, light, moderate, and vigorous physical activity, but a significant increase $(P<0.0005)$ in vigorous activity was observed in the intervention group at 10 weeks when compared to baseline [17]. In the first ten weeks, sedentary screen time decreased in the intervention group (from $10.5 \pm$ 5.5 to $9.3 \pm 4.9 \mathrm{~h} /$ week $)(P<0.05)$ and increased in the control group (from $9.3 \pm 5.7$ to $12.3 \pm 7.2 \mathrm{~h} /$ week) $(P<$ 0.09 ). In the same period, both groups registered increases in BMI (intervention: from 17.1 to 17.4; control: from 18.0 to 18.3) and systolic blood pressure (intervention: from 102.9 to $107.8 \mathrm{mmHg}$; control: from 99.6 to $110.2 \mathrm{mmHg}$ ) [17].

In a study by Graf et al. [18] entitled "Playing active video games increased energy expenditure in children," energy expenditure rates were evaluated for children playing exergames (DDR and Wii Bowling and Boxing) in relation to treadmill walking. Both gaming and treadmill walking were associated with significantly higher energy expenditure rates, maximal oxygen uptake $\left(\mathrm{V}_{2}\right)$, and heart rate (HR) when compared with watching television. However, among the exergames, DDR (skill level 2) involved the highest levels of energy expenditure (3.3 times resting levels), followed by Wii Boxing (2.9 and 3.3 times resting levels for boys and girls, resp.). Wii Boxing produced the greatest changes in heart rate (boys: $127 \mathrm{bpm}$; girls: $140 \mathrm{bpm}$ ), but DDR (skill level 2) performed best at raising the expired ventilatory rate (boys: $18.9 \mathrm{~L} / \mathrm{min}$; girls: $17.6 \mathrm{~L} / \mathrm{min}$ ), $\dot{\mathrm{VO}} 2$ (boys: $15.8 \mathrm{~mL} / \mathrm{kg} / \mathrm{min}$; girls: $13.2 \mathrm{~mL} / \mathrm{kg} / \mathrm{min}$ ), and rating of perceived exertion (boys: 13; girls: 16, Borg scale).

In 2009, Haddock et al. published "The addition of a video game to stationary cycling: the impact on energy expenditure in overweight children." During the $20 \mathrm{~min}$ experiment, energy expenditure was significantly higher $(P<0.01)$ while riding the bike as it controlled the video game $(4.4 \pm 1.2 \mathrm{Kcal} / \mathrm{min})$ than when riding the bike by itself $(3.7 \pm$ $1.1 \mathrm{Kcal} / \mathrm{min})$. The peak $\dot{\mathrm{V}} \mathrm{O}_{2}$ was $21.9 \pm 6.2 \mathrm{~mL} \cdot \mathrm{kg}^{-1} \cdot \mathrm{min}^{-1}$ with the game added and $19.3 \pm 5.7 \mathrm{~mL} \cdot \mathrm{kg}^{-1} \cdot \mathrm{min}^{-1}$ without the game, indicating a significant $(P<0.05)$ difference. However, no statistically significant difference was observed in heart rate (bicycle + game: $146.0 \pm 21.4 \mathrm{bpm}$, equivalent to $70 \%$ of age-predicted maximum $\mathrm{HR}$, versus bicycle alone: $142.4 \pm 18.8 \mathrm{bpm}$, equivalent to $68 \%$ of age-predicted maximum HR) nor in the rating of perceived exertion (bicycle + game: $3.2 \pm 2.8$; bicycle alone: $3.6 \pm 2.3$, Omni scale) [19].

In the study "Energy cost of exergaming," by Bailey and McInnis [20], all of the exergames evaluated, (Cybex Trazer, LightSpace, Sportwall, DDR, Nintendo Wii and Xavix) elevated energy expenditure to moderate or vigorous intensity when compared to rest $(P<0.05)$. Energy cost was the highest for XaviX Jackie Chan Alley Run and Sportwall, followed by LightSpace Bug Invasion, Cybex Trazer Goalie Wars, Dance Dance Revolution, and Nintendo Wii Boxing. Nevertheless, no difference in energy cost was observed between children with BMI below and above the 85th percentile, regardless of the game evaluated [20].

In "Effects of active video games on body composition: a randomized controlled trial," Maddison et al. [21] evaluated the effect of exergaming (Play3, Kinetic, and Sport e Dance Factory) on the body composition and physical fitness of 322 overweight and obese children. The participants were requested to play exergames (intervention group) for 60 minutes of moderate-to-vigorous physical activity on most days of the week or to play conventional video games (control group). At 24 weeks, significant differences were observed between the groups with regard to BMI $(-0.24$; 95\% CI: $-0.44,0.05 ; P=0.02$ ) (intervention: $24.8 \pm 3.6$ versus control: $25.8 \pm 4.2)$, percentage body fat $(-0.83 \%$; $95 \%$ CI: $-1.54 \%,-0.12 \% ; P=0.02$ ) (intervention: $29.8 \pm 7.2 \%$ versus control: $31.1 \pm 6.3 \%)$, and fat mass $(-0.80 \mathrm{~kg} ; 95 \% \mathrm{CI}$ : $-1.36,-0.24 \mathrm{~kg} ; P=0.005)$ (intervention: $19.0 \pm 7.1 \mathrm{~kg}$ versus control: $20.3 \pm 6.3 \mathrm{~kg}$ ).

In a recent study, "The effects of exergaming on physical activity in a third-grade physical education class," Shayne et al. [22] compared the effects of exergaming and traditional physical education on physical activity among 4 active children who were not overweight. Physical activity was significantly greater for exergaming than for physical education (Charlie $24 \%$ versus 6\%; Hugo $33 \%$ versus $-5 \%$; Desmond $31 \%$ versus $7 \%$; and Sawyer $41 \%$ versus $6 \%$ ). A similar pattern was observed for the percentage of physical activity engaged in when given the opportunity (Charlie 32\% versus $14 \%$; Hugo $42 \%$ versus $10 \%$; Desmond $37 \%$ versus $11 \%$; and Sawyer $47 \%$ versus 14\%). The exergames associated with the highest levels of activity, were Monster 434 and DDR. Interestingly, in exergaming students engaged in physical activity $82.5 \%$ of the time they had an opportunity to do so, as opposed to $48.8 \%$ in physical education [22].

\section{Discussion}

One limitation of our study was the small number of articles that met the selection criteria. Certainly, this failure was due to unusual and innovative character.

Childhood obesity is among other things associated with discrepancies between energy consumption and expenditure, resulting in a positive energy balance and, consequently, increased fat mass [23]. The adoption of a healthy lifestyle through a combination of diet and physical activity can potentially improve the anthropometric profile and body composition.

The studies show that the problem is potentiated by the lack of opportunity for physical activity in the current school setting due to the emphasis laid on professionalizing education in detriment to activities with energy expenditure compatible with the needs of children of school age $[4,24,25]$.

In fact, in articles that were studied, it has been suggested that $70 \%-80 \%$ of children and adolescents of both genders do not follow the minimum recommendations for daily physical activity $[26,27]$ and that physical inactivity is highly prevalent in this population [28]. Not surprisingly, there is evidence that low levels of physical activity are strongly associated with the development of childhood obesity [29]. 
Influenced by their environment, children and adolescents are leading increasingly sedentary lives using gadgets for everyday tasks which previously required more physical activity. Seen in this light, technology appears to have a negative impact on health in several published studies.

However, the advent of exergaming technology may usher in a change of paradigm by associating entertainment with health promotion and, potentially, contributing to the fight against childhood obesity [6].

To do so, children of school age must engage in moderateto-vigorous physical activity at least 60 minutes a day. Activities should be fun, stimulating, and challenging, involving diversified tasks [30]. Research shows that the association of tasks with pleasure and recreation increases adherence to interventions [31-33]. The playful nature of exergaming makes it possible to go beyond purely physical and biological aspects and attribute a meaning to the activity [34].

Exergaming technology offers users a different reality, one in which everything is faster and more attractive [35, page 132 ] and chances of success are greater. Here, children can have the experience of practicing sports with actual excitement, inserted in an arena surrounded by cheering crowds, overcome limits by breaking records, and simulate a sports award ceremony [35].

Within this context, as pointed out by Sinclair et al. [10], quoted by Vaghetti et al. [36], exergaming may constitute attractive, entertaining, and efficient means of engaging in physical activity while gaining fitness and improving motor skills.

In addition, according to Daley [37], exergaming increases energy expenditure during free time, making children more active and replacing sedentary time with healthy behaviors. Unlike conventional sedentary video games, exergames require full-body involvement in a number of different ways [38]. The fact that games can be played at home, with the participation of the whole family, is of no small relevance in the fight against childhood obesity.

Despite the relevance of the present review to health promotion and, more specifically, the fight against childhood obesity, this study is limited by the small number of publications currently available for a meaningful review of the literature, by the novelty and innovative nature of the health concepts involved, and by the absence of statistical analysis.

However, exergaming offers new and exciting horizons to be explored by researchers and healthcare professionals engaged in the fight against childhood obesity. The use of exergaming helps children and adolescents adopt a more active lifestyle which retains the fun, magic, and pleasure associated with play. However, the adoption of these practices should be rational and, if possible, overseen by a physical educator to prevent repetitive strain injury and osteomuscular disorders.

\section{Conclusions}

Based on a systematic review of the literature, exergaming, a modality of serious games, was found to lead to a more active lifestyle by increasing the level of physical activity, energy expenditure, and cardiorespiratory function and by reducing body fat and sedentary behaviors. In this light, technology may be viewed as an effective strategy for the encouragement of active and healthy behaviors and as an aid in the fight against childhood obesity. Exergaming technology appears to have a considerable potential in this respect, encouraging positive behaviors. However, more discussion is needed on strategies employing attractive interventions to fight the growing problem of childhood obesity around the world.

\section{Acknowledgments}

The authors would like to thank CAPES (Brazilian Government Program for Continuing Higher Education) and FUNCAP (Ceará State Foundation for Research Support) for financial support.

\section{References}

[1] M. Ray and K. R. Jat, "Effect of electronic media on children," Indian Pediatrics, vol. 47, no. 7, pp. 561-568, 2010.

[2] A. E. Baughcum, L. A. Chamberlin, C. M. Deeks, S. W. Powers, and R. C. Whitaker, "Maternal perceptions of overweight preschool children," Pediatrics, vol. 106, no. 6, pp. 1380-1386, 2000.

[3] R. J. Hancox, B. J. Milne, and R. Poulton, "Association between child and adolescent television viewing and adult health: a longitudinal birth cohort study," The Lancet, vol. 364, no. 9430, pp. 257-262, 2004.

[4] M. M. Carvalhal, M. C. Padez, P. A. Moreira, and V. M. Rosado, "Overweight and obesity related to activities in Portuguese children, 7-9 years," European Journal of Public Health, vol. 17, no. 1, pp. 42-46, 2007.

[5] A. C. T. Corso, G. V. Gilberto, G. M. R. Fiates, B. A. S. Schmitz, G. D. Ricardo, and F. A. G. Vasconcelos, "Fatores comportamentais associados ao sobrepeso e à obesidade em escolares do Estado de Santa Catarina," Revista Brasileira de Estudos de População, vol. 29, no. 1, 2012.

[6] T. Baranowski and L. Frankel, "Let's get technical! gaming and technology for weight control and health promotion in children," Childhood Obesity, vol. 8, no. 1, pp. 34-37, 2012.

[7] L. S. Machado, R. M. Moraes, and F. Nunes, Abordagens Práticas de Realidade Virtual e Aumentada, Serious Games para Saúde e Treinamento Imersivo, SBC, Porto Alegre, Brazil, 2009.

[8] K. Johnsen, A. Raij, A. Stevens, D. S. Lind, and B. Lok, "The validity of a virtual human experience for interpersonal skills education," in Proceedings of the 25th SIGCHI Conference on Human Factors in Computing Systems (CHI '07), pp. 1049-1058, May 2007.

[9] D. R. Michael and S. Chen, Serious Games: Games That Educate, Train, and Inform, Thomson, Boston, Mass, USA, 2006.

[10] S. J. Sinclair, P. Hingston, and M. Masek, "Considerations for the design of exergames," in Proceedings of the 5th International Conference on Computer Graphics and Interactive Techniques in Australia and Southeast Asia, pp. 289-296, 2007.

[11] C. A. O. Vaghetti and S. S. C. Botelho, "Ambientes virtuais de aprendizagem na educação física: uma revisão sobre a utilização de Exergames," Ciências \& Cognição, vol. 15, no. 1, 2010.

[12] E. J. Lyons, D. F. Tate, S. E. Komoski, P. M. Carr, and D. S. Ward, "Novel approaches to obesity prevention: effects of game enjoyment and game type on energy expenditure in active video 
games," Journal of Diabetes Science and Technology, vol. 6, no. 4, pp. 839-848, 2012.

[13] K. Linde and S. N. Willich, "How objective are systematic reviews? Differences between reviews on complementary medicine," Journal of the Royal Society of Medicine, vol. 96, no. 1, pp. 17-22, 2003.

[14] L. Graves, G. Stratton, N. D. Ridgers, and N. T. Cable, "Energy expenditure in adolescents playing new generation computer games," British Journal of Sports Medicine, vol. 42, no. 7, pp. 592594, 2008.

[15] C. Ni Mhurchu, R. Maddison, Y. Jiang, A. Jull, H. Prapavessis, and A. Rodgers, "Couch potatoes to jumping beans: a pilot study of the effect of active video games on physical activity in children," International Journal of Behavioral Nutrition and Physical Activity, vol. 5, article 8, 2008.

[16] R. R. Mellecker and A. M. McManus, "Energy expenditure and cardiovascular responses to seated and active gaming in children," Archives of Pediatrics and Adolescent Medicine, vol. 162, no. 9, pp. 886-891, 2008.

[17] A. E. Maloney, T. Carter Bethea, K. S. Kelsey et al., "A pilot of a video game (DDR) to promote physical activity and decrease sedentary screen time," Obesity, vol. 16, no. 9, pp. 2074-2080, 2008.

[18] D. L. Graf, L. V. Pratt, C. N. Hester, and K. R. Short, "Playing active video games increases energy expenditure in children," Pediatrics, vol. 124, no. 2, pp. 534-540, 2009.

[19] B. L. Haddock, S. R. Siegel, and L. D. Wikin, "The addition of a video game to stationary cycling: the impact on energy expenditure in overweight children," The Open Sports Sciences Journal, vol. 1, no. 2, pp. 42-46, 2009.

[20] B. W. Bailey and K. McInnis, "Energy cost of exergaming: a comparison of the energy cost of 6 forms of exergaming," Archives of Pediatrics and Adolescent Medicine, vol. 165, no. 7, pp. 597-602, 2011.

[21] R. Maddison, L. Foley, C. Ni Mhurchu et al., "Effects of active video games on body composition: a randomized controlled trial," American Journal of Clinical Nutrition, vol. 94, no. 1, pp. 156-163, 2011.

[22] R. K. Shayne, V. A. Fogel, R. G. Miltenberger, and S. Koehler, "The effects of exergaming on physical activity in a third-grade physical education class," Journal of Applied Behavior Analysis, vol. 45, no. 1, pp. 211-215, 2012.

[23] C. J. Dodd, "Energy regulation in young people," Journal of Sports Science and Medicine, vol. 6, no. 3, pp. 327-336, 2007.

[24] A. Jáuregui, S. Villalpando, E. Rangel-Baltazar, J. CastroHernández, Y. Lara-Zamudio, and I. Méndez-GómezHumarán, "The physical activity level of Mexican children decreases upon entry to elementary school," Salud Pública de México, vol. 53, no. 3, pp. 228-236, 2011.

[25] A. M. Toigo, "Níveis de atividade física na educação física escolar e durante o tempo livre em crianças e adolescentes," Revista Mackenzie de Educação Física e Esporte, vol. 6, no. 1, pp. 45-56, 2007.

[26] C. Tudor-Locke, R. P. Pangrazi, C. B. Corbin et al., "BMIreferenced standards for recommended pedometer-determined steps/day in children," Preventive Medicine, vol. 38, no. 6, pp. 857-864, 2004.

[27] J. Scott Duncan, G. Schofield, and E. K. Duncan, "Step count recommendations for children based on body fat," Preventive Medicine, vol. 44, no. 1, pp. 42-44, 2007.
[28] R. A. Fernandes, I. F. Freitas Jr., J. R. Cardoso, E. R. Vaz Ronque, M. R. Loch, and A. R. De Oliveira, "Association between regular participation in sports and leisure time behaviors in Brazilian adolescents: a cross-sectional study," BMC Public Health, vol. 8, article 329, 2008.

[29] C. S. C. Rosa, K. P. Messias, R. A. Fernandes, C. B. Silva, H. L. Onteiro, and I. F. Freitas Junior, "Atividade física habitual de crianças e adolescentes mensurada por pedômetro e sua relação com índices nutricionais," Revista Brasileira de Cineantropometria \& Desempenho Humano, vol. 13, no. 1, pp. 22-28, 2011.

[30] Instituto Do Desporto De Portugal, “Orientações da União Europeia para a actividade física: políticas recomendadas para a promoção da saúde e do bem-estar. Instituto do Desporto de Portugal," Lisboa, Portugal, 2009, http://www.idesporto.pt/ ficheiros/File/Livro_IDPfinalJan09.pdf.

[31] C. Buonani, R. A. Fernandes, L. S. Silveira et al., "Prevenção da síndrome metabólica em crianças obesas: uma proposta de intervenção," Revista Paulista de Pediatria, vol. 29, no. 2, pp. 86192, 2011.

[32] L. S. Poeta, M. F. S. Duarte, I. C. B. Giuliano, and J. C. Farias Júnior, "Intervenção interdisciplinar na composição corporal e em testes de aptidão física de crianças obesas," Revista Brasileira de Cineantropometria \& Desempenho Humano, vol. 14, no. 2, pp. 134-143, 2012.

[33] C. L. Davis, N. K. Pollock, J. L. Waller et al., "Exercise dose and diabetes risk in overweight and obese children: a randomized controlled trial," The Journal of the American Medical Association, vol. 308, no. 11, pp. 1103-1112, 2012.

[34] J. Huizinga, Homo Ludens: o Jogo Como Elemento da Cultura, Perspectiva, São Paulo, Brazil, 5th edition, 2007.

[35] V. M. Kenski, "O impacto da mídia e das novas tecnologias de comunicação na educação física," Revista de Educação Física, vol. 1, no. 2, pp. 129-133, 1995.

[36] C. A. O. Vaghetti, P. N. Mustaro, and S. S. C. Botelho, "Exergames no ciberespaço: uma possibilidade para Educação Física," X SBGames-Salvador-BA, 2011, http://www.sbgames.org/ sbgames2011/proceedings/sbgames/papers/cult/full/92287_1 .pdf.

[37] A. J. Daley, "Can exergaming contribute to improving physical activity levels and health outcomes in children?" Pediatrics, vol. 124, no. 2, pp. 763-771, 2009.

[38] A. F. O. Baracho, F. J. Gripp, and M. R. Lima, "Os exergames e a educação física escolar na cultura digital," Archives of Pediatrics and Adolescent Medicine, vol. 34, no. 1, pp. 111-126, 2012. 


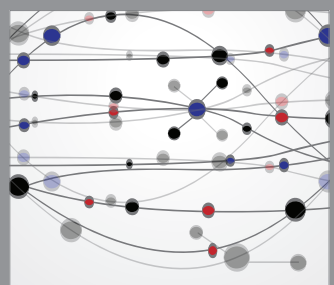

The Scientific World Journal
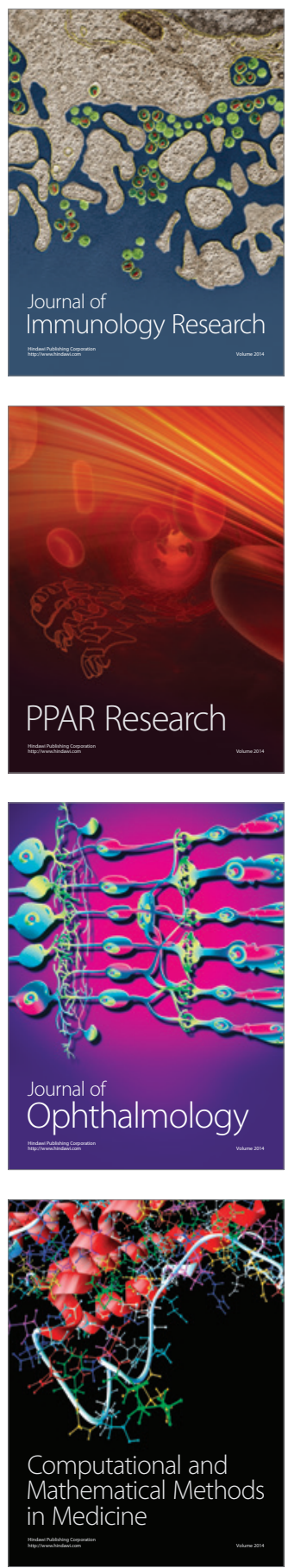

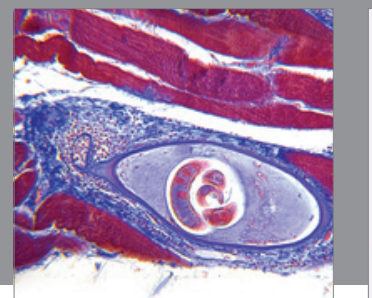

Gastroenterology

Research and Practice
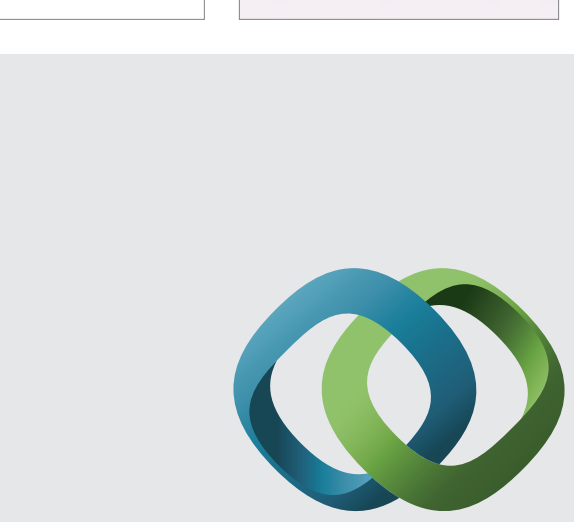

\section{Hindawi}

Submit your manuscripts at

http://www.hindawi.com
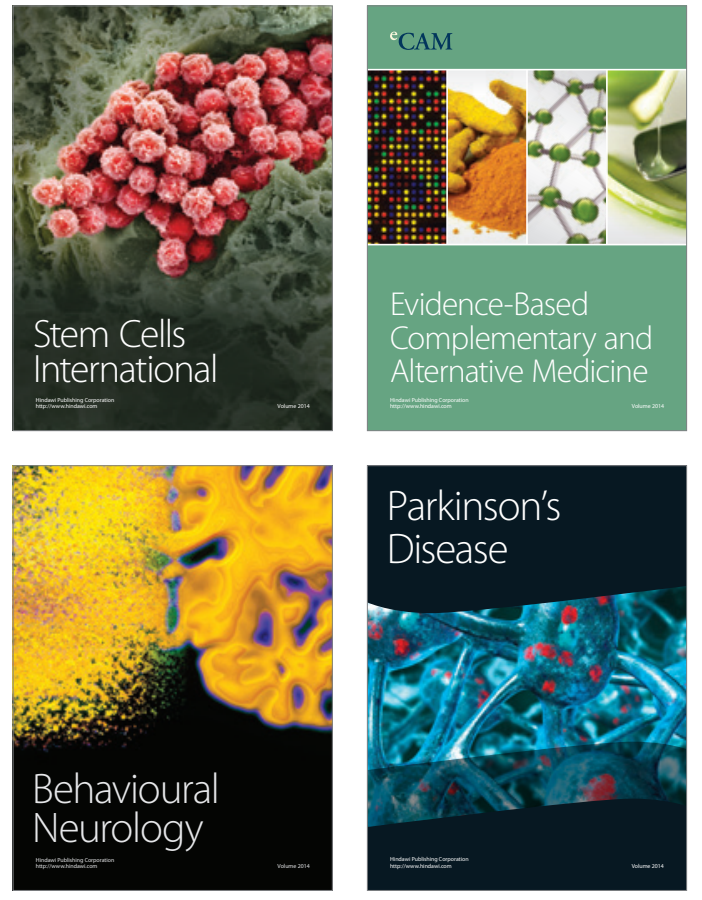
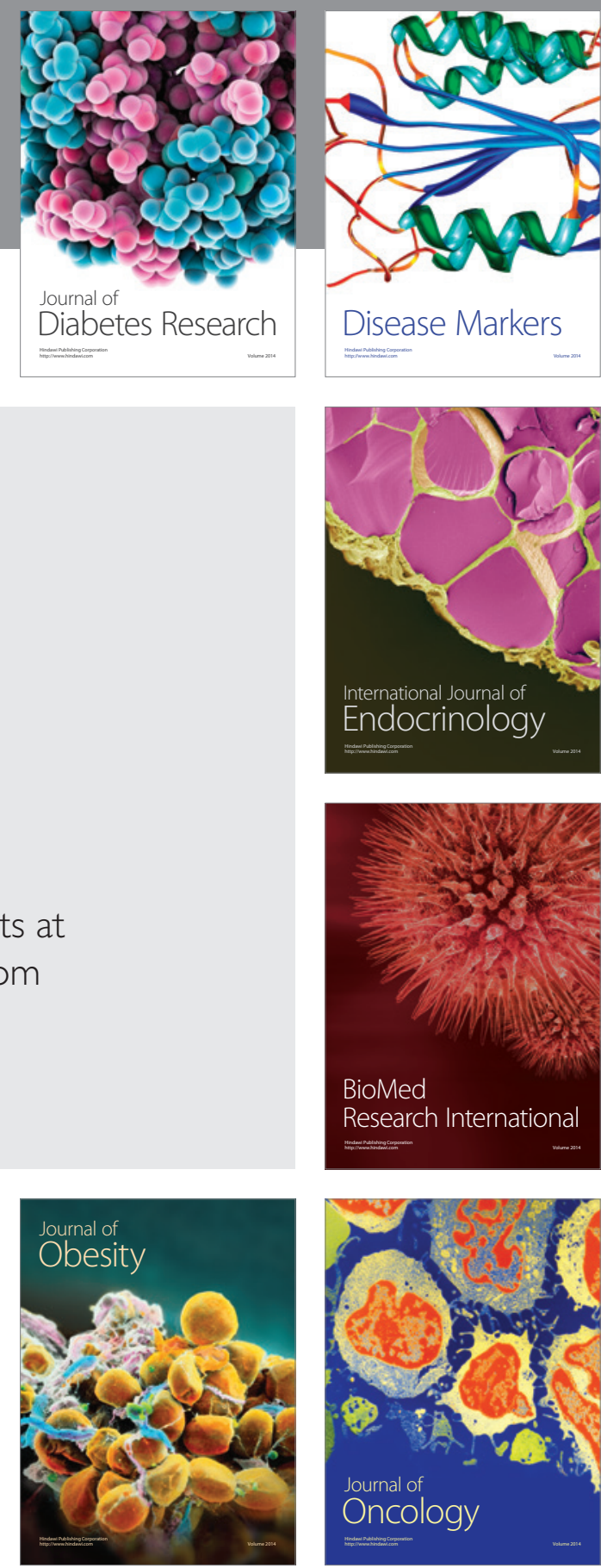

Disease Markers
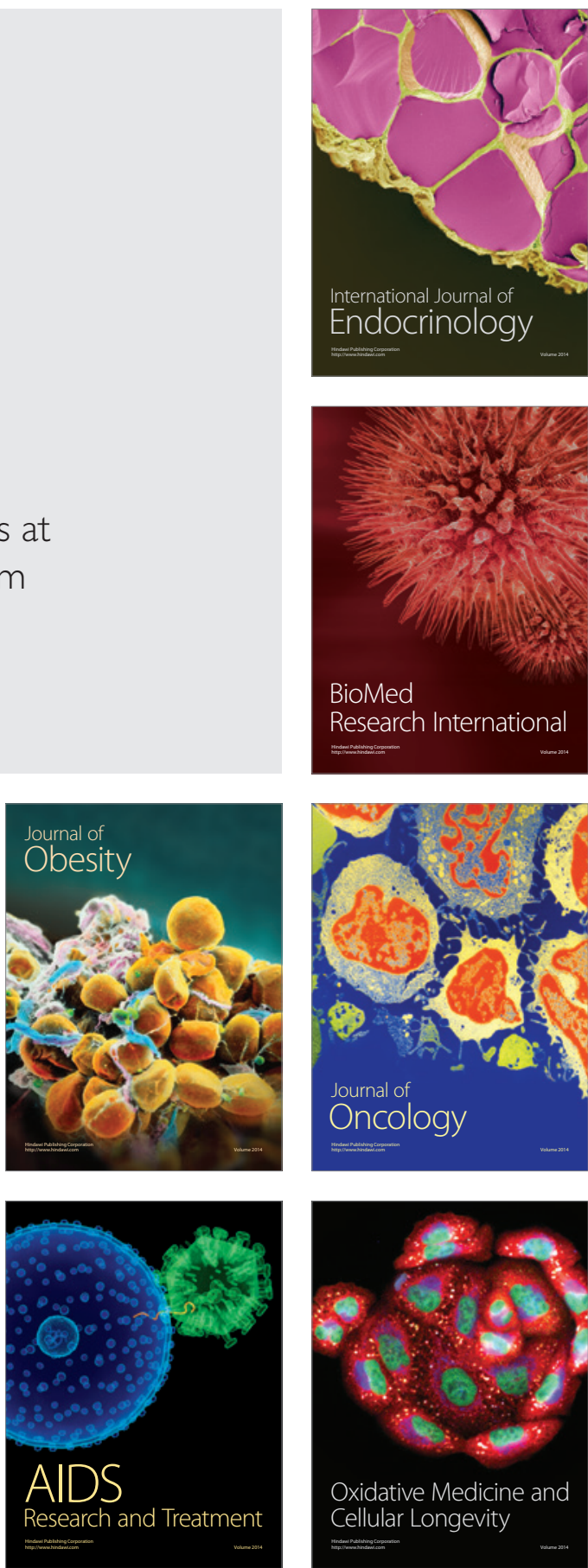